\title{
Competing with Free: \\ The Impact of Movie Broadcasts on DVD Sales and Internet Piracy
}

\author{
Michael D. Smith and Rahul Telang \\ \{mds, rtelang\}@andrew.cmu.edu \\ H. John Heinz III School of Public Policy and Management \\ Carnegie Mellon University \\ Pittsburgh, PA 15213
}

This Version: August 2006

Acknowledgements: The authors thank Erik Brynjolfsson, Marvin Sirbu, Lowell Taylor, Patrick Wagstrom and seminar participants at the 2006 INFORMS Marketing Science Conference, the 2006 Statistical Challenges in Electronic Commerce Conference, the University of Florida, MIT, Purdue University and Carnegie Mellon University for valuable comments on this research. We thank Pisit Chartbanchachai, Samita Dhanasobhon, Lawrence Gioia, Reshma Kane, Sang Dong Lee, Thomas Oliver, and Amita Pimple for excellent research assistance. Both authors acknowledge the National Science Foundation for generous financial support provided through CAREER award IIS-0118767 (Smith) and CAREER award CNS-0546009 (Telang). 


\title{
The Impact of Movie Broadcasts on Internet Piracy and DVD Sales:
}

\author{
Analysis and Implications for the Broadcast Flag Debate
}

\begin{abstract}
$\underline{\text { ABSTRACT }}$
Movie studios have long believed that the presence of home recording technology significantly damages the marketability of movies broadcast on free television. This issue has gained renewed importance recently with the advent of high-definition digital television, causing the movie studios to argue that unless copy protection is included in digital television standards, it will no longer be profitable for them to show movies through unprotected over-the-air broadcast channels. Their concern is that digital transmission standards and personal video recorders will allow consumers and pirates to make perfect digital copies of movie broadcasts, resulting in increased piracy and reduced demand for DVDs.

We empirically analyze these concerns and find that the dominant impact of movie broadcasts is to stimulate DVD sales. DVD sales increase by an average of 345-399\% immediately after a movie is shown on broadcast TV. These sales gains are approximately four times larger than sales gains from copy protected cable broadcasts.

However, we also find evidence that movie broadcasts stimulate piracy and that movies with pirated copies available through BitTorrent experience a lower DVD sales gain after broadcast than movies that do not have pirated copies available through BitTorrent do.

These findings should be should be encouraging to movie studios exploring new ways to monetize their content. These findings should also provide new empirical evidence in the Congressional debate over the broadcast flag and other copy protection technologies in over-the-air TV broadcasts.
\end{abstract}

Keywords: Information goods, Movie broadcasts, movie promotion, DVD Sales, Broadcast flag, consumer surplus. 


\section{Introduction}

“They say without protection, high value content will not be made available on the broadcast medium. Given the circumstances and the potential harm to creators, it is appropriate to offer some baseline protection.”

Statement of FCC Commissioner Jonathan S. Adelstein, in Federal Communications Commission, Report and Order adopting Digital Broadcast Content Protection, November 4, 2003. (FCC 2003, page 69)

"Not one of the proponents of a broadcast-flag or similar 'marking' scheme has adduced a record of empirical data demonstrating a current or imminent infringement problem with digital television that needs a regulatory solution from the Commission.” Public Knowledge and Consumer Union reply comments before the Federal Communications Commission in the matter of Digital Broadcast Copy Protection, February 19, 2003. (Godwin et al. 2003, page 6)

Since the advent of the first VCR, movie studios have believed that the ability of consumers to freely record television broadcasts will significantly harm the marketability of movies that are broadcast on television. The argument is intuitive. Once a consumer is able to make a copy of a movie shown on television, why would they ever consider purchasing a copy of that movie in a similar format?

This concern has gained renewed interest recently with the development of high definition digital television (DTV), which will advance the integration between the television and the computer. Today, DTV conversion devices for computers can be purchased for around \$100, and some analysts estimate that 300,000 to 500,000 such cards were in use in computers in 2003 (Godwin et al. 2003). ${ }^{1}$

\footnotetext{
${ }^{1}$ The industry may also be concerned about the increased penetration of Digital Video Recorders (DVRs), which are more consumer friendly and allow higher quality copies than were possible with analog VCR tapes. Pasztor (2006) quotes from an industry report that estimates DVR penetration of $10 \%$ for cable systems and $28 \%$ for satellite systems, with estimates of $50 \%$ penetration on both systems by 2010 .
} 
Thus, while in the analog world of the VCR, consumers could make an imperfect, low resolution copy of the movie, HDTV allows consumers to make a perfect high resolution digital copy of the movie. Using analog technology it was very difficult for consumers to edit commercials out of their recordings, while the integration between digital video recorders and computers makes it trivially easy for consumers to edit commercials out of their recorded movie broadcasts. Finally, while analog copies of movies were hard to duplicate and share, digital copies of movies can be easily copied and shared, raising the specter of rampant piracy of movies shown on television.

This is not an idle concern for movie studios where media sales, primarily This "sweetheart deal" was the result of savvy negotiating on the part of the studios early in the development of the DVD standard. Indeed the DVD standard emerged as an enormous boon to the movie industry. For example, Time Warner's library of movies appreciated by $\$ 7$ billion between the time the DVD was introduced in 1996 to 2004 (Epstein 2005). With this in mind, studios are also concerned about protecting future revenue streams from next generation high definition video player standards such as the Blu Ray and HD-DVD formats, and from emerging digital download services, such as CinemaNow and Apple’s iTunes video store.

In raising these concerns, some studio executives have gone so far as to argue that unless copy protection technology is included in over-the-air DTV standards, it will no longer be profitable for them to show their movies on (unprotected) over-the-air network broadcasts. That instead, they will choose to broadcast their content only on cable channels, which currently have basic copy protection for digital television content. For example, in comments before the Federal Communication Commission, Viacom, the parent company to CBS, made the following observation:

"Viacom believes that [Digital Television] sales and broadband subscriptions have reached the 'tipping point' at which it can no longer afford to expose its content to piracy. A broadcast flag regime is needed now to protect the value of our important assets or we must withhold our quality HD digital content.”

Viacom comments before the Federal Communications Commission in the matter of Digital Broadcast Copy Protection, December 6, 2002. (Lucey 2002, page 8) 
Similar statements were able made by Disney/ABC (Fox 2002) and NBC (LeBeau 2002). The crux of this argument is that when movies are broadcast in DTV format, it will inevitably lead to increased piracy of these movies through Internet file sharing networks, which in turn, will lead to reduced sales of movies in retail channels - a serious concern for an industry where DVD sales made up 46\% (\$14.9 billion) of total revenue in 2002 (Epstein 2005, p. 20; PBS 2005). ${ }^{2}$ Essentially, the studios are arguing that they can't compete with free copies of movies made available through over-the-air broadcasts and potentially through pirate networks.

However, in spite of these arguments, we believe that it is striking that nowhere does the public record contain any empirical evidence of whether DTV broadcasts actually stimulate piracy or reduce DVD sales in a way that might cause the movie studios to find it more profitable to show their content on cable systems versus over-the-air broadcasts.

With this in mind, the goal of this research is to analyze two main empirical questions. First, what impact do movie broadcasts have on DVD sales? And second, what impact do movie broadcasts have on the supply of and demand for pirated copies of movies? These empirical questions are important because they parallel the arguments of the movie studios in advocating the broadcast flag. They also shed light on the incentives of the movie studios to broadcast their content in over-the-air versus cable venues. Finally, they shed light on the impact of movie broadcasts on the subsequent market for movies purchased on DVDs - which is one of four factors used in U.S. copyright law in determining whether a particular consumer use of copyrighted material should be considered an allowable "fair use."

To do this we gather a new dataset including all movies shown on over-the-air television broadcast networks and the four most popular ad-supported cable networks from July 12, 2005 to March 3, 2006 (excluding the Christmas holiday season). For these movies we collect data on sales level at Amazon.com and piracy levels at two major BitTorrent tracker sites. We find that, movie broadcasts significantly stimulate DVD sales — leading to a 345-399\% increase in sales immediately following broadcast, and that the increase in sales for broadcast movies is between four to five times larger than the increase in sales from cable movies. However, we also find that movie broadcasts result in a statistically significant increase in the demand for pirated copies of

\footnotetext{
${ }^{2}$ Moreover, the studios' margins on DVD sales are higher than their margins in most of their other lines of business. Studios only pay $20 \%$ of DVD revenues to the various artist and production unions, keeping the remaining $80 \%$.
} 
the movies. In particular, for movies shown over-the-air, the increase in piracy is about $150 \%$. We also find that broadcast movies that have a BitTorrent tracker available at the time of broadcast experience a smaller gain in sales than movies that do not have BitTorrent trackers available. On the other hand, movies shown on cable networks do not experience a statistically significant increase in piracy. ${ }^{3}$

The remainder of this paper proceeds as follows. In Section 2, we provide policy background on the broadcast flag debate. In Section 3, we review the relevant literature pertaining to the impact of broadcasts and piracy on product sales. In Section 4, we discuss our data. In Section 5, we present our empirical models and results. Finally, in Section 6, we discuss the implication of our findings, limitation of our analysis, and areas of future work.

\section{Broadcast Flag Policy Background}

In the face of concerns about piracy from over-the-air high definition television broadcasts, the movie studios proposed a "broadcast flag" copy protection scheme to the Federal Communications Commission (FCC). The stated goal of the broadcast flag was "to prevent the indiscriminate redistribution of [over-the-air broadcast] content over the Internet or through similar means” (Welborn 2005, page 5). The broadcast flag is a 16-bit field inserted into the digital television bit-stream for over-the-air broadcasts. This flag can either be set to protect or not protect the content as the discretion of the copyright holder. Broadcast flag compliant devices would listen for the flag, assume it to be set to protect if it was not found, maintain copy protection within the device, and only output the signal over protected outputs (e.g., High Definition Multimedia Interface (HDMI) standard for Digital Visual Interface (DVI) connections) or in a degraded form (approximately equal in resolution to current NTSC television broadcasts). The studios have argued that the broadcast flag copy protection scheme provides them with a similar level of piracy protection to existing copy protection schemes used in cable and satellite broadcasts.

The industry touted this as a narrowly focused solution with minimal impact to consumers. For example, Dan Glickman in testimony before congress stated that

\footnotetext{
${ }^{3}$ Though once we control for the "prime time" effect, even movies shown on cable network show increase in piracy.
} 
"The broadcast flag rule is targeted and narrowly focused on a single problem. The only activity affected by the broadcast flag is the indiscriminate redistribution of digital broadcast television over the Internet.” (Glickman 2005).

In spite of this, consumer groups raised several concerns related to potential collateral impacts of the broadcast flag. First, consumer groups argued that the broadcast flag may limit some consumer "fair uses" of TV broadcasts currently allowed under copyright law (see Center for Democracy and Technology 2003, p. 23-24; ALA 2004, p. 6, 18, 45-50; von Lohmann et al. 2003, p. 24). The U.S. Supreme Court's 1984 decision in Universal versus Sony allows consumers to record TV broadcasts to watch at a later time (a.k.a. time-shifting) or to transfer these TV broadcasts to another medium (a.k.a. space-shifting). Consumer groups argued that some time-shifting and space-shifting activities would be curtailed by limiting the transfer of TV broadcasts to compliant hardware that is contained on the same local network.

Such limits on time- and space-shifting activities may also assist innovative pricing and content distribution strategies. For example, in testimony before Congress on broadcast flag legislation, Dan Glickman, President of the Motion Picture Association of America, observed that

\begin{abstract}
"We are embracing DRM [Digital Rights Management] technologies so that we can offer consumers more choices at a greater variety of price points: one consumer may want to purchase a permanent copy of a movie while another may want to watch it only once and at a lower price. To sustain the viability of this array of different offers, however, we must be able to maintain the distinction among them. Thus, we need to provide technical safeguards to discourage, for example, the copying of a 'view once' option that has been selected by a consumer.” (Glickman 2005).
\end{abstract}

Consumer groups also argued that, for a variety of reasons, the broadcast flag is unlikely to significantly reduce piracy, the very problem it was designed to solve (see Center for Democracy and Technology 2003, p. 20, 31-32; ALA 2004, p. 3, 54-55; von Lohmann et al. 2003, p. 9-13). Notably, the broadcast flag doesn't cover existing DTV decoders, which will continue to be able to receive content without copy restrictions, and will continue to ignore the broadcast flag settings. Furthermore, it is currently possible to decode DTV programming in software, and software distribution is significantly harder to control than hardware distribution (Burger 2005). In 
both cases, these potential sources of piracy have the characteristic of a "break-once breakeverywhere" system where a leak from one source will readily propagate to the entire network (Biddle et al. 2002).

Consumer groups also observed that the broadcast flag might stifle innovation by requiring hardware and software manufacturers to comply with restrictive standards (Center for Democracy and Technology 2003, p. 17-18, 21; ALA 2004, p. 6-8; von Lohmann et al. 2003, p. 16, 22, 28-30; Godwin et al. 2003, p. 13, 16-18; Grover 2005, p. 16). Notably, consumer groups argued that the increasing integration of the computer and the television may place the FCC in the difficult position of regulating computer hardware and software design (see Center for Democracy and Technology 2003, p. 22). A related concern is that the broadcast flag regulation's requirement that demodulators are "not user modifiable" is at odds with open source software development, which by definition allows user modification (Center for Democracy and Technology 2003, p. 22, 30-31).

A final set of concerns raised by consumer groups pertained to the potential that the broadcast flag will confuse consumers, which might delay adoption of DTV technology (Center for Democracy and Technology, 2003, p. 23). For example, legacy DTV players will not be compatible with Broadcast Flag demodulators. Thus, a DTV television set purchased before the broadcast flag legislation will, in all likelihood, not be compatible with a Broadcast Flag compatible Digital Video Recorder (DVR). This would require the consumer to purchase new equipment to maintain compatibility. It is also possible that the new hardware requirements will increase the price of hardware either by requiring additional equipment or reducing innovation and competition among manufacturers (see ALA 2004, p. 6).

In weighing the competing concerns of consumer groups, consumer electronics manufacturers, and TV and movie studios, the FCC seemed to rely heavily on statements by the movie industry that without copy protection, the resulting piracy and lost media sales would be so severe that they would find it more profitable to broadcast their content through (protected) cable and satellite outlets than through over-the-air broadcast outlets. The FCC may have been concerned that, if movie studios removed their "high value" movie content from over-the-air broadcast channels, it would delay the United State's transition from analog to digital TV. 
For example, in the broadcast flag rulemaking, the FCC noted that enacting the broadcast flag "will not only alleviate the concerns of content owners, but also will ensure the continued availability of high value DTV content to consumers through broadcast outlets.” (FCC 2003, p. 5-6). These concerns were also reflected in the comments of FCC commissioners on the broadcast flag rulemaking. For example, Commissioner Abernathy noted that "by protecting against digital piracy, we also encourage entertainment companies to deliver via free over-the-air broadcast its most valuable programs” (FCC 2003, p. 65). Similarly, Commissioner Adelstein noted that "[broadcasters] say without protection, high value content will not be made available on the broadcast medium. Given the circumstances and the potential harm to creators, it is appropriate to offer some baseline protection” (FCC 2003, p. 69). Maybe most to the point, Commissioner Copps stated that

"Given digital media's susceptibility to indiscriminate mass online distribution, content producers may have significantly greater incentives to broadcast high-value content if there are in place at least basic protection technologies. If denied such protection in one medium (e.g. free, over-the-air broadcast television) they will migrate their new content to other media (e.g., subscription cable television). Such as result would likely discourage new digital content in the broadcast medium and also retard the statutorily-mandated transition to digital television...I am also guided by the need to protect consumers in our quest to encourage digital content and to expedite the digital transition. The reason we are promoting digital television, after all, is to benefit consumers, not companies.” (FCC 2003, p. 65)

The FCC's concern about the speed of the transition to DTV derives from the fact that DTV, in addition to offering higher quality pictures, also makes more efficient use of scarce bandwidth. Television broadcasters are given free access to public spectrum, which would be worth billions of dollars if it were sold at auction. Because of DTV's more efficient use of spectrum, the transition from analog to digital TV will free up $108 \mathrm{MHz}$ of spectrum in prime cellular frequencies. The New America Foundation estimated that this spectrum would be worth $\$ 50$ billion at auction (Rast 2005). 
However, freeing up this spectrum will require completion of the transition from analog to digital television transmission. From a public policy perspective, the cost and timing of this transition is heavily dependent on the penetration of DTV. In the original DTV legislation, analog television broadcasts would only cease in a particular region when $85 \%$ of that region's televisions were DTV compatible. While more recent legislation has placed a hard cutoff date of February 17, 2009 for the transition to Digital TV, at this point the government may feel an obligation to subsidize the purchase of digital to analog converter boxes for the remaining consumers in a region who do not have DTV compatible TV sets.

Possibly influenced by the movie industry's statements about the likely impact of DTV on piracy, in November 2003 the FCC enacted rule 47 CFR 73,9002(b) which required that all DTV demodulators sold in the United States would be broadcast flag compliant by July 2005. Following a lawsuit filed by the American Library Association and other consumer groups, the U.S. Court of Appeals for the D.C. Circuit overturned this FCC rule in May 2005 on the grounds that the FCC did not have Congressional authority to regulate hardware manufacturers. As of January of 2006 Congress has initiated hearings on whether to authorize the FCC to enact broadcast flag regulations.

\section{Literature}

In the literature, there is little empirical work on the impact of TV broadcast on media (e.g. DVD) sales. On one hand, TV broadcast may act as a marketing stimuli and generate increased demand. On the other hand, the TV broadcast could satisfy the consumer's desire to see the movie, resulting in decreased demand - a problem made more acute by consumer fair use rights to record broadcasted content and the increasing penetration of high quality DVR devices. TV broadcasts could also decrease demand if they increased the supply of and demand for pirated copies of the content.

Liebowitz (2004) is the only study we are aware of pertaining to the impact of TV penetration on the movie studio revenue. He shows that as TV penetration increased from the 1940's and 50's to the present, box office revenues fell sharply, while revenues from other sources such as movie

rental, pay cable have increased substantially. He observes that by opening up new revenue 
sources from broadcast licensing and downstream media sales, the net impact of TV penetration on the studios was almost certainly positive. However, Liebowitz notes that, owing to data limitations, this analysis is conducted at an aggregate level and cannot establish a causal link between individual movie broadcasts and increased media sales.

Our work also pertains to the literature on the impact of piracy on markets for information goods. Most of the work in this area has focused on software or music "piracy," and particularly on P2P file sharing networks and their impact on firm profitability. A prominent trend in the analytic literature has been to show that that piracy need not be bad for firms. Prasad and Mahajan (2003) argue that piracy may be good for a new product if the firm needs to establish initial user base and speed up diffusion. Gu and Mahajan (2005) show that because piracy removes the most price sensitive buyers from the market it can reduce price competition, benefiting sellers. Finally, Peitz and Waelbroeck (2003) show that piracy can act as a free "sample" that increases product awareness while Chellappa and Shivendu (2005).

The empirical work on piracy has focused on estimating the effect of piracy on legal demand, with somewhat mixed results. On one hand, Hui and Png 2003 find that piracy negatively affects the legal demand for software, and Rob and Waldfogel (2006) find that piracy decreased media consumption by 3.5\% in a sample of 500 University of Pennsylvania students. On the other hand, while Oberholzer and Strumpf (2004) find that music file sharing on P2P networks has no effect on CD sales. Bhattacharjee et al (2004) find that the impact of piracy depends on the popularity of the particular music CD, with less popular CDs facing higher piracy risks. Similarly, Blackburn (2004) uses a model that takes into account the differential impact of piracy and wellknown and unknown artists and finds that RIAA lawsuits have resulted in a 2.9\% increase in album sales during the 6 month period after the lawsuits were announced.

Analyzing piracy from a policy perspective, Gopal and Sanders (1998) show that govt. enforcement of intellectual property rights depends on the robustness of the domestic software industry. Finally, analyzing piracy from the perspective of supply, Byers et al. (2003) show that the majority of movies available on file sharing originate from studio leaks, as opposed to copies from DVDs or other commercial media. 
We also note that the impact of piracy on product markets is conceptually similar to the impact of used goods markets on new product sales (Ghose, Smith, and Telang (2006)), competition between traditional print copies of books and PDF copies of books (Kannan and Jain 2002), consumers' decisions to rent or purchase movies (Knox and Eliashberg 2005), and international movie release windows (Elberse and Eliashberg 2003).

From the perspective of empirical methods, our analysis relates to the growing empirical literature using Amazon's sales rank data to estimate the company's product-level sales. While Amazon.com does not provide product-level sales information for its products, the company does provide information about the sales ranking of products within a particular product category. Researchers have used this sales rank data to estimate Amazon's sales through direct empirical estimation (Brynjolfsson, Hu, and Smith 2003) and experimental calibration (Chevalier and Goolsbee 2003). Subsequent papers in the literature have used Chevalier and Goolsbee's experimental calibration technique in a variety of contexts (e.g., Chevalier and Mayzlin (2004); Smith and Telang (2004); Ghose and Sundararajan (2005); and Ghose, Smith, and Telang (2006)).

\section{Data}

Our data were collected from July 12, 2005 through November 23, $2005^{4}$ and from January 1, 2006 through March 3, 2006. We have eliminated all observations during the Christmas holiday season to avoid any potential counter-explanations that might occur during this time period (e.g., increased sales of DVD, reduction in piracy).

Our data consist of information on all movies shown on over-the-air broadcast channels and major ad-supported cable channels. With respect to over-the-air channels, we sampled all movies shown in national broadcasts on ABC, CBS, NBC, FOX, UPN, and WB networks. We used only national broadcasts because local affiliates have the option of slotting movies that will only be shown in a local region. We determined that a broadcast was national if it was shown in both the New York City and Los Angeles affiliates during the same time slot. We use the national (as opposed to local) broadcast as a partial control for audience size.

\footnotetext{
${ }^{4}$ November 23, 2005, is the day before Thanksgiving, the traditional start of the Christmas shopping season. Our results are not sensitive to this choice of dates. For example, eliminating all observations from November 1, 2005 to January 1, 2006 would result in a slight (and statistically insignificant) increase in the sales gains reported here.
} 
We also collected data from the four most popular ad-supported cable networks: TBS, TNT, USA, and Lifetime. We selected these four networks based on Nielsen Media Research viewership estimates (as reported by TelevisionWeek magazine) for the six-month period from March to August 2005. The four most popular channels were the same whether we considered total daily viewers or prime time viewers.

We collected data for each of these movie broadcasts from three primary sources. We collected broadcast information — broadcast date and time, broadcast duration, movie name and description, and whether the movie was shown in high definition format - from TitanTV.com. We used TitanTV because it is easily searchable and provided a 14-day advance notice before a movie's broadcast date. This advance notice, allowed us to obtain a baseline level of sales and piracy before broadcast. We used the Internet Movie Database (imdb.com) to obtain information on the theatrical release date, rental revenue, gross revenue, gross budget, and IMDB user star rating for each of the movies in our study.

Table 1: Sales Data Summary Statistics

\begin{tabular}{l|r|rrrr}
\hline \multicolumn{1}{c|}{ Variable } & \multicolumn{1}{c|}{ Obs. } & Mean & St. Dev. & Min & \multicolumn{1}{c}{ Max } \\
\hline Amazon Rank & 144,612 & 10,447 & 9,880 & 38 & 64,610 \\
List Price & 144,612 & 15.56 & 5.55 & 4.98 & 79.92 \\
Amazon Price & 144,612 & 13.20 & 4.27 & 4.98 & 41.23 \\
Amazon Star Rating & 143,814 & 3.81 & 0.64 & 1 & 5 \\
Broadcast Duration (Hours) & 144,612 & 2.21 & 0.38 & 1.5 & 4 \\
High Definition Format & 144,612 & 0.07 & 0.26 & 0 & 1 \\
Broadcast Network & 144,612 & 0.14 & 0.34 & 0 & 1 \\
Number of Discs in DVD & 144,612 & 1.09 & 0.36 & 1 & 5 \\
Ln(Gross Revenue (\$ Million)) & 125,755 & 17.42 & 1.19 & 10.53 & 19.69 \\
IMDB User Votes & 144,612 & 16,098 & 23,610 & 30 & 191,707 \\
Minutes Edited from Broadcast & 144,612 & 9.47 & 8.15 & 0 & 40 \\
\hline
\end{tabular}

Finally, we collected information about DVD characteristics and sales (rank) for each version of the movie available at Amazon.com. Many movies have separate wide screen, full screen, and in some cases special edition, or unrated editions. ${ }^{5}$ For each of the DVD versions, we collected product characteristics including list price, release date, MPAA rating, aspect ratio, number of

\footnotetext{
${ }^{5}$ We did not collect data on box sets that contain multiple different movies, even if one of the movies in the box set was present in our sample.
} 
discs, and sound quality (e.g., Stereo, Dolby Surround, Dolby THX). We also collected Amazon marketplace information including the Amazon price, the lowest used price, the Amazon users' star rating of the movie, and the movie's sales rank. This information was collected hourly for two-weeks before and after the movie was shown, and daily thereafter. We do not include observations that occur after the second showing of a movie in our data, to focus our attention on the sales gain from the first showing. Our final sample contains 522 broadcast movies and 618 DVD titles. The summary statistics for our sales data are shown in Table $1{ }^{6}$

We use the DVD sales rank as a proxy for the number of products sold at Amazon. Amazon.com lists the rank of products sold in each product category, with 1 corresponding to the highest selling product, 2 to the second highest selling product, and so on. Following Brynjolfsson, Hu, and Smith (2003) and Chevalier and Goolsbee (2003) we assume that the relationship between sales and sales rank follows a Pareto distribution: ${ }^{7}$

Quantity $=\beta_{1}$ Rank $^{\beta_{2}}$

This relationship can be parameterized using either direct observation of sales and ranks for select titles, typically obtained from product suppliers (see Brynjolfsson, Hu, and Smith 2003) or by means of an experiment (see Chevalier and Goolsbee 2003). Lacking supplier data, we apply Chevalier and Goolsbee's experimental technique, by finding 2 DVDs with high rank (low sales) and observing their rank over the course of several weeks to estimate the number of daily sales. We then ordered 7 copies of the DVDs in an hour, observing the initial and final rank. This allows us to obtain two points on the curve, which we can then use to determine the slope $\left(\beta_{2}\right)$ of equation (1) in log-log space. We performed this experiment on July 1 and July 8, 2005 for two separate DVDs and found the estimated $\beta_{2}$ parameter was equal to -1.61 in both cases. We performed this experiment again on February 8, 2006 for two additional DVDs, and found estimated $\beta_{2}$ parameters of -1.76 and -1.81 respectively. We use the average of the four $\beta_{2}$ estimates $(-1.70)$ in our subsequent calculations.

\footnotetext{
${ }^{6}$ This table includes all data from 14 days before broadcast date through 28 days after the broadcast date consistent with our regressions below.

${ }^{7}$ This technique has also been applied in a variety of other studies, including Chevalier and Mayzlin (2004); Ghose, Smith, and Telang (2006); and Ghose and Sundararajan (2005).
} 
QuickTime ${ }^{\mathrm{TM}}$ and a

are needed to see this picture.

\section{Figure 1: Mininova.org Screen}

Our piracy data comes from piratebay.org and mininova.org, two public tracker sites for the BitTorrent protocol. We selected BitTorrent to track piracy for two reasons. First, BitTorrent is currently the most popular protocol for sharing large files, such as movie files. Second, the design of the BitTorrent protocol is such that all nodes participating in a file download report their status to the tracker every 20 seconds. Thus, tracker sites such as piratebay and mininova know, in (near) real-time, the number of users providing the entire file (a.k.a. seeds), the number of users actively downloading the file (a.k.a. leechers), and the number of cumulative downloads. We selected piratebay and mininova as data sources because they were among the most popular BitTorrent tracker sites during our study period, ${ }^{8}$ and these sites also list the current number of seeds, leechers, and downloads for each of their trackers. (Figure 1 shows a sample screen from mininova.org.)

\footnotetext{
${ }^{8}$ For example, Gil (2006) lists both piratebay and mininova among the five most popular BitTorrent tracker sites.
} 
For each of the movies in our dataset, we search for trackers matching the movie title and general description at both piratebay and mininova both before and after the broadcast date. For all matching trackers we collect the date the tracker was added to the respective tracker site, the file size and daily observations of the number of seeds, leechers, and cumulative downloads. Our final dataset covers the period of October 28, 2005 through March 3, 2006. As above, we exclude the Christmas holiday period (November 23, 2005 through January 1, 2006) to avoid the possibility that piracy levels are systematically different during this time period. The summary statistics for our piracy data are shown in Table $2 .^{9}$

Table 2: Piracy Data Summary Statistics

\begin{tabular}{l|r|rrrr}
\hline \multicolumn{1}{c|}{ Variable } & \multicolumn{1}{c|}{ Obs. } & Mean & St. Dev. & Min & \multicolumn{1}{c}{ Max } \\
\hline Broadcast Network & 3,847 & 0.13 & 0.34 & 0 & 1 \\
Leechers & 3,847 & 13.90 & 26.27 & 0 & 235 \\
Seeds & 3,847 & 3.47 & 8.15 & 0 & 68 \\
Daily Downloads & 3,554 & 3.81 & 10.77 & 0 & 189 \\
\hline
\end{tabular}

It is important to note that DVDs are typically released 3-6 months after the end of the theatrical release (Epstein 2005) and first shown on television 18 months to 3 years after the DVD release. This will influence the number of daily downloads per trackers and will also suggest that our measured increase in piracy will be conservative.

\section{Results}

\subsection{DVD Sales Results}

To estimate the effect of movie broadcast on DVD sales, we create a set of time dummy variables that control for the sales levels before and after the broadcast. For notational simplicity, the dummy variable $\mathrm{D}(\mathrm{a}, \mathrm{b})$ will be equal to one for a to $\mathrm{b}$ days before or after the broadcast. Thus, $\mathrm{D}(-2,-1)$ equals 1 for all time periods from 2 to 1 day before broadcast starts on the east coast of the United States and $\mathrm{D}(1,2)$ equals 1 for all time periods 1 to 2 days after broadcast ends on the west cost. We set $\mathrm{D}(0,0)$ to be equal to 1 for all time periods from the start of the broadcast on the east coast to the end of the broadcast on the west coast.

\footnotetext{
${ }^{9}$ Our summary statistics only include observations from 14 days before broadcast to 7 days after broadcast consistent with our regressions below.
} 
We then estimate a model with DVD-level fixed effects to see how sales change before and after a movie is broadcast on over-the-air television or cable. A fixed effect model ensures that sale changes are captured within a DVD. An unfortunate characteristic of fixed effect estimation is that we cannot include any variables that are constant within DVD (and therefore collinear withthe DVD fixed effect). We will relax this requirement using random effects models below. The fixed effect model we estimate is

$\operatorname{Ln}\left(\right.$ Rank $\left._{\mathrm{it}}\right)=\xi$ Price $_{i t}+\delta \mathrm{D}_{\mathrm{t}}+\varepsilon_{i t}$

where $i$ indexes a movie and $t$ indexes time. $\xi$ and $\delta$ are the vectors of coefficients to be estimated, where $\delta$ captures the effect of movie broadcast on DVD sales, our variable of interest. Note that we start observing sales rank two weeks before broadcast, and we eliminate any observations one month after broadcast (to avoid conflating our results with natural declines in sales due to product life-cycle issues). Thus, the left out variables in this regression is the sales level two weeks before broadcast. Our results for this regression are shown in Table 3.

The crucial variables in our model are the dummy variables on time. Note that these coefficients are either statistically insignificant, or slightly positive before a movie is shown. Thus, there may be a small decline in sales before a movie is broadcast. $\mathrm{D}(0,0)$ shows a larger and statistically significant decrease in log rank, implying an increase in sales. Recall that $\mathrm{D}(0,0)$ is a dummy variable that equals one from the time that the movie starts showing on the east coast until it stops showing on the west cost. Thus, this coefficient is likely picking up an increase in sales from east coast and central time zone viewers after the movie ends. Further, after a movie is shown, the sales coefficients are initially large and statistically significant, returning to the baseline sales level after two to four weeks. Comparing results across movie types and broadcast outlets we see that the gains for movies shown over-the-air in HD format are similar to, but generally higher than movies shown in lower resolution format - with the coefficients for both types of over-the-air broadcasts significantly higher than the coefficients from movies shown on cable channels. 
Table 3: Impact of Movie Broadcasts on Sales Rank (Fixed Effects)

\begin{tabular}{|c|c|c|c|}
\hline Indep. Vars. & Broadcast (HD) & Broadcast (SD) & Cable \\
\hline $\mathrm{D}(-7,-6)$ & $0.049^{*}(0.021)$ & $0.107^{* *}(0.037)$ & $0.014^{* *}(0.006)$ \\
\hline $\mathrm{D}(-6,-5)$ & $0.021(0.021)$ & $0.123^{* *}(0.037)$ & $0.021^{* *}(0.005)$ \\
\hline$D(-5,-4)$ & $0.031(0.021)$ & $0.104^{* *}(0.038)$ & $0.028^{* *}(0.006)$ \\
\hline $\mathrm{D}(-4,-3)$ & $0.119^{* *}(0.020)$ & $0.179^{* *}(0.038)$ & $0.038^{* *}(0.005)$ \\
\hline$D(-3,-2)$ & $0.003(0.020)$ & $0.144^{* *}(0.036)$ & $0.022^{* *}(0.005)$ \\
\hline $\mathrm{D}(-2,-1)$ & $0.021 \quad(0.020)$ & $0.020 \quad(0.036)$ & $0.031^{* *}(0.005)$ \\
\hline $\mathrm{D}(-1,0)$ & $-0.044^{*}(0.019)$ & $0.044 \quad(0.034)$ & 0.007 (0.005) \\
\hline $\mathrm{D}(0,0)$ & $-0.241^{* *}(0.035)$ & $-0.270^{* *}(0.063)$ & $-0.062^{* *}(0.010)$ \\
\hline $\mathrm{D}(0,1)$ & $-0.878^{* *}(0.020)$ & $-0.973^{* *}(0.033)$ & $-0.372^{* *}(0.006)$ \\
\hline $\mathrm{D}(1,2)$ & $-0.899^{* *}(0.020)$ & $-0.724^{* *}(0.034)$ & $-0.290^{* *}(0.007)$ \\
\hline $\mathrm{D}(2,3)$ & $-0.643^{* *}(0.021)$ & $-0.601^{* *}(0.034)$ & $-0.199^{* *}(0.007)$ \\
\hline $\mathrm{D}(3,4)$ & $-0.495^{* *}(0.021)$ & $-0.391^{* *}(0.034)$ & $-0.134^{* *}(0.007)$ \\
\hline $\mathrm{D}(4,5)$ & $-0.459^{* *}(0.021)$ & $-0.264^{* *}(0.034)$ & $-0.111^{* *}(0.007)$ \\
\hline $\mathrm{D}(5,6)$ & $-0.326^{* *}(0.021)$ & $-0.131^{* *}(0.034)$ & $-0.056^{* *}(0.007)$ \\
\hline $\mathrm{D}(6,7)$ & $-0.260^{* *}(0.021)$ & $-0.209^{* *}(0.034)$ & $-0.037^{* *}(0.007)$ \\
\hline $\mathrm{D}(7,14)$ & $-0.199^{* *}(0.013)$ & $-0.067^{* *}(0.021)$ & $-0.012^{* *}(0.004)$ \\
\hline $\mathrm{D}(14,21)$ & $-0.037^{* *}(0.014)$ & $-0.003 \quad(0.021)$ & $-0.003(0.004)$ \\
\hline $\mathrm{D}(21,28)$ & $0.022(0.014)$ & $-0.046 \quad(0.023)$ & $0.039^{* *}(0.004)$ \\
\hline Amazon Price & $0.119^{* *}(0.004)$ & $0.013^{* *}(0.019)$ & $0.078^{* *}(0.001)$ \\
\hline Constant & $6.470^{* *}(0.066)$ & $8.649^{* *}(0.282)$ & $7.872^{* *}(0.020)$ \\
\hline No. of Obs. & 14,913 & 4,496 & 159,198 \\
\hline No. of Groups & 34 & 10 & 571 \\
\hline
\end{tabular}

The dependent variable is $\ln ($ sales rank). Standard errors are listed in parenthesis; ** and * denote significance at 0.01 and 0.05 , respectively. All models use DVD-level fixed effects.

To interpret the values of the dummy variables in terms of changes in sales, recall that $\operatorname{Ln}($ Sales) $=\beta * \operatorname{Ln}($ Rank) where $\beta=-1.70$. It is straightforward to show that the percentage increase in sales resulting from a coefficient $\delta_{i}$ is

$\Delta$ Sales $=e^{\beta \delta_{i}}-1$ 


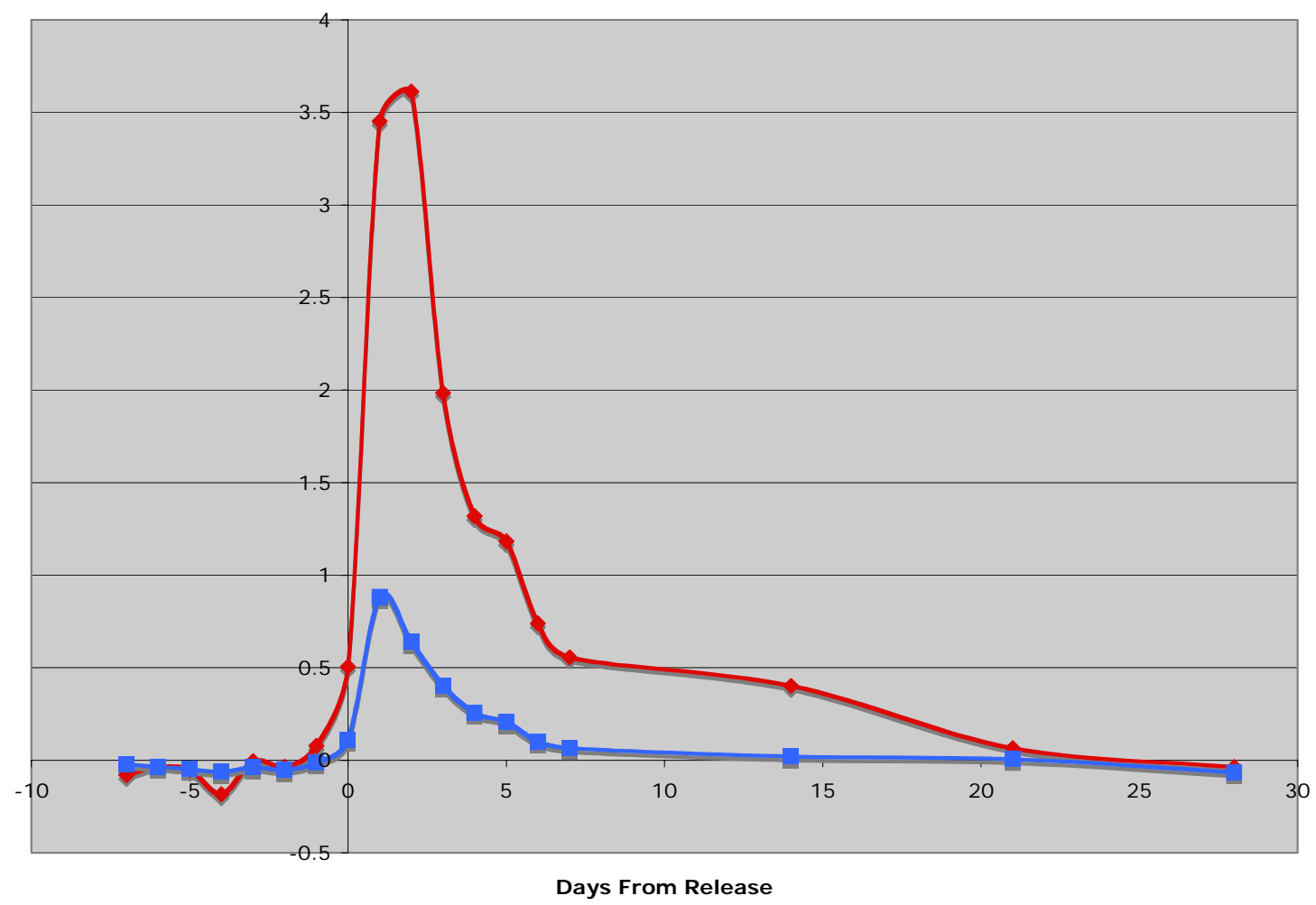

Figure 2: Over-The-Air HD vs. Cable Sales Gain

Thus, movies shown in HD on an over-the-air channel experience, on average, a 345\% increase in sales in the 24 hour period after the movie is shown, compared to an $88 \%$ increase in sales for movies shown on cable channels. Figure 2 graphically compares the sales response for over-theair HD and cable broadcasts.

To include additional DVD-level controls, we need to estimate a random effects model. The random effects model assumes that the DVD-level effects incorporated into the random effects error term are uncorrelated with the explanatory variables. If this assumption does not hold, the random effects coefficients are inconsistent. We use a Hausman test to evaluate this assumption, comparing the baseline regression results under the fixed and random effects model. This test fails to reject the null hypothesis that the random effects assumptions hold at any reasonable confidence level. 
Table 5: Impact of Movie Broadcasts on Sales Rank (Random Effects)

\begin{tabular}{r|rr} 
Indep. Vars. & Broadcast $(H D \& S D)$ & Cable \\
\hline $\mathrm{D}(-7,-6)$ & $0.005(0.019)$ & $0.012^{*}(0.006)$ \\
$\mathrm{D}(-6,-5)$ & $-0.028(0.019)$ & $0.022^{* *}(0.006)$ \\
$\mathrm{D}(-5,-4)$ & $-0.018(0.019)$ & $0.028^{* *}(0.006)$ \\
$\mathrm{D}(-4,-3)$ & $0.054^{* *}(0.019)$ & $0.032^{* *}(0.006)$ \\
$\mathrm{D}(-3,-2)$ & $-0.053^{* *}(0.018)$ & $0.011^{*}(0.006)$ \\
$\mathrm{D}(-2,-1)$ & $-0.032(0.018)$ & $0.020^{* *}(0.005)$ \\
$\mathrm{D}(-1,0)$ & $-0.082^{* *}(0.017)$ & $-0.001(0.005)$ \\
$\mathrm{D}(0,0)$ & $-0.300^{* *}(0.032)$ & $-0.076^{* *}(0.010)$ \\
$\mathrm{D}(0,1)$ & $-0.946^{* *}(0.018)$ & $-0.355^{* *}(0.006)$ \\
$\mathrm{D}(1,2)$ & $-0.934^{* *}(0.018)$ & $-0.261^{* *}(0.007)$ \\
$\mathrm{D}(2,3)$ & $-0.732^{* *}(0.019)$ & $-0.159^{* *}(0.008)$ \\
$\mathrm{D}(3,4)$ & $-0.556^{* *}(0.019)$ & $-0.116^{* *}(0.007)$ \\
$\mathrm{D}(4,5)$ & $-0.498^{* *}(0.019)$ & $-0.091^{* *}(0.007)$ \\
$\mathrm{D}(5,6)$ & $-0.337^{* *}(0.019)$ & $-0.040^{* *}(0.008)$ \\
$\mathrm{D}(6,7)$ & $-0.295^{* *}(0.019)$ & $-0.028^{* *}(0.008)$ \\
$\mathrm{D}(7,14)$ & $-0.236^{* *}(0.012)$ & $-0.005(0.004)$ \\
$\mathrm{D}(14,21)$ & $-0.075^{* *}(0.012)$ & $-0.001(0.004)$ \\
$\mathrm{D}(21,28)$ & $-0.057^{* *}(0.013)$ & $0.037^{* *}(0.005)$ \\
Amazon Price & $0.123^{* *}(0.004)$ & $0.087^{* *}(0.002)$ \\
Amazon Star Rating & $-0.219(0.193)$ & $-0.242^{* *}(0.013)$ \\
Movie Duration & $0.187(0.362)$ & $-0.053(0.111)$ \\
No. of Groups & $-0.829^{*}(0.361)$ & $-0.576^{* *}(0.094)$ \\
Ln(Gross Revenue) & $-0.586^{*}(0.307)$ & $-0.120^{* *}(0.034)$ \\
IMDB User Rating & $0.127(0.232)$ & $-0.319^{* *}(0.038)$ \\
Minutes Edited & $-0.007(0.021)$ & $-0.006(0.004)$ \\
Constant & $18.065^{* *}(4.996)$ & $13.347^{* *}(0.524)$ \\
\hline & 17,923 & 136,222 \\
No. of Obs & 41 & 566 \\
\hline
\end{tabular}

The dependent variable is $\ln ($ sales rank). Standard errors are listed in parenthesis; ${ }^{* *}$ and $*$ denote significance at 0.01 and 0.05 , respectively.

We report the random effects regression results in Table 5. The first column represents all broadcast movies and the second represents all cable movies. ${ }^{10}$ We see that that absolute increase in sales in the first 24-hour period after a movie is shown on an over-the-air broadcast is $399 \%$, compared to $83 \%$ for cable movies. Thus, the relative sales increase for over-the-air movies is, if anything, higher under the random effects model than the fixed effect model. We also note that the other coefficients have the expected signs: movies with higher user ratings (either Amazon or IMDB) have higher sales though result for Amazon stars is not in expected direction for Cable.

\footnotetext{
${ }^{10}$ Our results are very similar if we were to compare HD or SD broadcast movies to cable movies.
} 
Movies with a higher gross revenue, more discs included with the DVD, or more content (minutes) edited out of the TV broadcast also have higher sales, although not all coefficients are statistically significant for these variables.

In total, our results suggest that both cable and over-the-air movies experience a large, statistically significant increase in sales immediately following their broadcast, and this increase in sales typically persists several weeks before returning to its baseline level. We also note that movies broadcast over-the-air have larger increase in sales than movies shown over cable do. Some of which is probably attributed to difference in the popularity of the movies shown as well as the number of viewers watching those movies (typically over-the-air channel movies would be watched by larger audience). Our findings show that the benefits of DTV broadcast through promoting media purchases far outweigh any potential cannibalization effect. Our findings also provide strong evidence that the movie industry would not benefit from moving content from overthe-air to cable channels, at least from the perspective of DVD sales. We discuss these findings in more detail below.

\subsection{Piracy Results}

In the second part of our analysis, we examine how TV broadcast affects the piracy of these movies on file-sharing network. The models we estimate are

$\left\{\right.$ download $_{i t}$, lechers $_{i t}$, seeder $\left._{i t}\right\}=\lambda D_{t}+\varepsilon_{i t}$

where our dependent variables include separately the daily download rate, the number of seeders, and the number of leechers for each movie tracker on each day. Our independent variables include the time dummies. One of the problems in estimating privacy models is that usually there is a natural decline in the number of downloads or number of leechers for each tracker. Thus, we limit our observations to one week after the movie is broadcast to keep our estimation window small enough to avoid picking up the natural decline trend. We use a daily dummy variable for each day after the broadcast, and leave the two weeks before broadcast as the left out variable. Thus, this structure allows us to estimate how piracy levels changes relative to average piracy 
levels in the two weeks prior to broadcast. Our results are shown in Table 6 for broadcast channels and Table 7 for cable channels. ${ }^{11}$

Table 6: Impact of Movie Broadcasts on Piracy (Fixed Effects) for Broadcast Channels

\begin{tabular}{r|rrr}
\hline \multicolumn{1}{c|}{ Indep. Vars. } & Daily Downloads & \multicolumn{1}{c}{ Seeds } & \multicolumn{1}{c}{ Leechers } \\
\hline $\mathrm{D}(0,0)$ & $1.94(1.23)$ & $0.82(0.50)$ & $0.05(1.16)$ \\
$\mathrm{D}(0,1)$ & $4.61^{* *}(0.80)$ & $2.33^{* * *}(0.41)$ & $3.57^{* *}(0.80)$ \\
$\mathrm{D}(1,2)$ & $1.89^{*}(0.80)$ & $1.14^{* *}(0.41)$ & $2.70^{* *}(0.80)$ \\
$\mathrm{D}(2,3)$ & $1.55(0.80)$ & $0.75(0.41)$ & $2.25^{* *}(0.80)$ \\
$\mathrm{D}(3,4)$ & $0.85(0.81)$ & $0.71^{*}(0.42)$ & $1.89^{*}(0.82)$ \\
$\mathrm{D}(4,5)$ & $-0.04(0.81)$ & $0.57(0.42)$ & $0.99(0.81)$ \\
$\mathrm{D}(5,6)$ & $0.09(0.81)$ & $0.22(0.42)$ & $0.07(0.81)$ \\
$\mathrm{D}(6,7)$ & $0.91(0.81)$ & $0.32(0.42)$ & $0.719(0.81)$ \\
Constant & $3.08^{* *}(0.39)$ & $2.62^{* *}(0.13)$ & $12.39^{* *}(0.35)$ \\
\hline No. of Obs & 454 & 454 & 454 \\
No. of Groups & 38 & 38 & 38 \\
\hline
\end{tabular}

The dependent variable is daily downloads (column 1), number of leechers (column 2), and number of seeds (column 3). Standard errors are listed in parenthesis; ** and * denote significance at 0.01 and 0.05 , respectively. All models use tracker-level fixed effects.

Our results show significant increase in piracy immediately after movies are broadcast (except for leechers). Further, the magnitude of these changes is non-trivial. For example, our results suggest that in the day after a movie is broadcast there is a $150 \%$ increase in the day after broadcast (7.7 downloads per day on our two public trackers versus a baseline level of 3.1 downloads per day), and a 61\% increase on the second day after broadcast. Each of these results are statistically significant at the $1 \%$ level. Similarly, there are statistically significant increases in the number of seeders of $89 \%$ and $44 \%$ on the first and second day after broadcast, and a $29 \%$ and $22 \%$ increase in the number of leechers on the first and second day after broadcast.

We ran the same models on cable broadcast movies. Our results are shown in Table 7. The cable results reveal no statistically significant increase in downloads or seeds, and only a small (7\%) increase in leechers on the second day after broadcast (followed by declines in leechers on the fourth through seventh day after broadcast). However, we note that Cable movies are generally shown at various times unlike broadcast movies which are typically shown in prime-time. Once we control for "prime-time” effect for Cable (8-10pm) then piracy levels increase for Cable mov-

\footnotetext{
${ }^{11}$ Leechers reflect both supply and demand as, in the BitTorrent network, individuals downloading a file also share (in the vast majority of cases) share the portions of the file they have already downloaded with other downloaders.
} 
ies as well although the magnitude is smaller. In short, over-the-air movie broadcasts tend in stimulate both DVD sales and piracy, and these increases are substantially higher than they are for cable broadcasts.

Table 7: Impact of Movie Broadcasts on Piracy (Fixed Effects) for Cable Channels

\begin{tabular}{r|rrr}
\hline \multicolumn{1}{c|}{ Indep. Vars. } & Daily Downloads & \multicolumn{1}{c}{ Seeds } & \multicolumn{1}{c}{ Leechers } \\
\hline $\mathrm{D}(0,0)$ & $0.20(0.90)$ & $-0.13(0.34)$ & $0.73(0.89)$ \\
$\mathrm{D}(0,1)$ & $0.41(0.43)$ & $0.13(0.16)$ & $0.08(0.42)$ \\
$\mathrm{D}(1,2)$ & $0.40(0.44)$ & $0.25(0.16)$ & $1.12^{* *}(0.43)$ \\
$\mathrm{D}(2,3)$ & $0.70(0.43)$ & $0.23(0.16)$ & $0.17(0.43)$ \\
$\mathrm{D}(3,4)$ & $-0.19(0.44)$ & $0.03(0.17)$ & $-1.21^{* *}(0.43)$ \\
$\mathrm{D}(4,5)$ & $0.12(0.43)$ & $-0.21(0.16)$ & $-1.61^{* *}(0.43)$ \\
$\mathrm{D}(5,6)$ & $-0.66(0.44)$ & $-0.08(0.16)$ & $-1.69^{* *}(0.43)$ \\
$\mathrm{D}(6,7)$ & $-0.46(0.44)$ & $-0.25(0.17)$ & $-1.36^{* *}(0.44)$ \\
Constant & $3.84^{* *}(0.15)$ & $3.62^{* *}(0.05)$ & $15.06^{* *}(0.14)$ \\
\hline No. of Obs & 3,189 & 3,448 & 3,448 \\
No. of Groups & 255 & 259 & 259 \\
\hline
\end{tabular}

The dependent variable is daily downloads (column 1), number of leechers (column 2), and number of seeds (column 3). Standard errors are listed in parenthesis; ** and * denote significance at 0.01 and 0.05 , respectively. All models use tracker-level fixed effects.

The next major empirical question is whether increases in piracy are associated with lower DVD sales. To analyze this question, we compare the DVD sales gain for movies that have BitTorrent trackers at the time of their broadcast to the DVD sales gain among movies that do not have BitTorrent trackers at the time of broadcast. Our results are shown in Table 8 for broadcast (columns 1 \& 2) and cable (columns 3 \& 4) movies.

The results show that movies broadcast over-the-air which have BitTorrent trackers available have a substantially lower increase in sales than over-the-air movies that do not have BitTorrent trackers. For example, on the first and second day after broadcast, over-the-air movies with BitTorrent trackers see a $259 \%$ and $398 \%$ increase in sales respectively, versus a $296 \%$ and $572 \%$ increase for movies that do not have BitTorrent trackers. Conversely, cable movies have approximately the same sales gain irrespective of whether a BitTorrent tracker was available. ${ }^{12}$

\footnotetext{
${ }^{12}$ We see similar results for broadcast movies shown in HD and under a random effects model.
} 
These results are consistent with the piracy results reported above. We find a statistically significant increase in piracy among broadcast movies, and we find that movies where pirated copies were available have a lower increase in sales than other movies.

One concern with these results is that the difference in sales increase could be driven by selection bias that happens to be correlated with the presence or absence of a BitTorrent tracker. To test for this possibility we re-ran our results segmenting movies with similar average ranks prior to broadcast and for movies from similar genres, finding results consistent with those reported here. However, as these are only partial controls for potential selection bias, we report our results as suggestive, but not conclusive, evidence that increases in piracy cause decreases in DVD sales.

Table 8: Sales Increases for DVD with and without BitTorrent Trackers

\begin{tabular}{|c|c|c|c|c|}
\hline Indep. Vars. & $\begin{array}{c}\text { Broadcast } \\
\text { With BitTorrent }\end{array}$ & $\begin{array}{c}\text { Broadcast } \\
\text { Without BitTorrent }\end{array}$ & $\begin{array}{c}\text { Cable } \\
\text { With BitTorrent }\end{array}$ & $\begin{array}{c}\text { Cable } \\
\text { Without BitTorrent }\end{array}$ \\
\hline$\overline{D(-7,-6)}$ & $-0.05(0.04)$ & $-0.14(0.08)$ & $-0.07^{* *}(0.02)$ & $0.06^{* *}(0.02)$ \\
\hline $\mathrm{D}(-6,-5)$ & $-0.07(0.04)$ & $-0.12(0.07)$ & $-0.04^{*}(0.02)$ & $0.06^{* *}(0.02)$ \\
\hline $\mathrm{D}(-5,-4)$ & $0.01(0.04)$ & $-0.44^{* *}(0.07)$ & $0.04^{*}(0.02)$ & $0.09^{* *}(0.02)$ \\
\hline $\mathrm{D}(-4,-3)$ & $0.11^{* *}(0.04)$ & $-0.35^{* *}(0.07)$ & $0.09^{* *}(0.02)$ & $0.06^{* *}(0.02)$ \\
\hline$D(-3,-2)$ & $-0.09^{*}(0.04)$ & $-0.04(0.08)$ & $0.05^{* *}(0.02)$ & $0.14^{* *}(0.02)$ \\
\hline $\mathrm{D}(-2,-1)$ & $-0.16^{* *}(0.04)$ & $-0.18^{* *}(0.07)$ & $0.03(0.02)$ & $0.10^{* *}(0.02)$ \\
\hline $\mathrm{D}(-1,0)$ & $-0.16^{* *}(0.04)$ & $-0.14^{*}(0.07)$ & $-0.01(0.02)$ & $0.02(0.02)$ \\
\hline $\mathrm{D}(0,0)$ & $-0.21(0.06)$ & $-0.44^{* *}(0.11)$ & $-0.01(0.03)$ & $-0.13^{* *}(0.03)$ \\
\hline $\mathrm{D}(0,1)$ & $-0.75^{* *}(0.04)$ & $-0.81^{* *}(0.07)$ & $-0.23^{* *}(0.02)$ & $-0.39^{* *}(0.02)$ \\
\hline $\mathrm{D}(1,2)$ & $-0.94^{* *}(0.04)$ & $-1.12^{* *}(0.08)$ & $-0.25^{* *}(0.02)$ & $-0.19^{* *}(0.02)$ \\
\hline $\mathrm{D}(2,3)$ & $-0.76^{* *}(0.04)$ & $-0.85^{* *}(0.07)$ & $-0.08^{*}(0.03)$ & $-0.10^{* *}(0.02)$ \\
\hline $\mathrm{D}(3,4)$ & $-0.63^{* *}(0.04)$ & $-0.73^{* *}(0.08)$ & $-0.11^{* *}(0.03)$ & $-0.06^{* *}(0.02)$ \\
\hline $\mathrm{D}(4,5)$ & $-0.54^{* *}(0.05)$ & $-0.69^{* *}(0.08)$ & $-0.08^{* *}(0.04)$ & $-0.03(0.02)$ \\
\hline $\mathrm{D}(5,6)$ & $-0.49^{* *}(0.04)$ & $-0.50^{* *}(0.08)$ & $-0.19^{* *}(0.04)$ & $0.05^{*}(0.02)$ \\
\hline $\mathrm{D}(6,7)$ & $-0.45^{* *}(0.04)$ & $-0.44^{* *}(0.07)$ & $-0.15^{* *}(0.04)$ & $0.05^{*}(0.02)$ \\
\hline $\mathrm{D}(7,14)$ & $-0.34^{* *}(0.03)$ & $-0.54^{* *}(0.06)$ & $-0.06^{*}(0.02)$ & $0.04^{* *}(0.02)$ \\
\hline $\mathrm{D}(14,21)$ & $-0.24^{* *}(0.04)$ & $-0.45^{* *}(0.06)$ & $0.22^{* *}(0.03)$ & $0.04^{*}(0.02)$ \\
\hline $\mathrm{D}(21,28)$ & $0.07(0.04)$ & $-0.41^{* *}(0.07)$ & (dropped) & $-0.23^{* *}(0.05)$ \\
\hline Amazon & $0.15(0.01)$ & $0.10^{* *}(0.01)$ & $0.07^{* *}(0.01)$ & $0.24^{* *}(0.01)$ \\
\hline Price & & & & \\
\hline Constant & $5.52^{* *}(0.13)$ & $6.33^{* *}(0.15)$ & $7.70^{* *}(0.09)$ & $6.38^{* *}(0.18)$ \\
\hline No. of Obs. & 3,464 & 1,430 & 7,169 & 9,766 \\
\hline $\begin{array}{r}\text { No. of } \\
\text { Groups } \\
\end{array}$ & 12 & 13 & 51 & 78 \\
\hline
\end{tabular}

The dependent variable is $\ln ($ sales rank). Standard errors are listed in parenthesis; $* *$ and $*$ denote significance at 0.01 and 0.05 , respectively. All models use DVD-level fixed effects. 
In summary, our results indicate that over-the-air movie broadcasts stimulate both media sales and to a lesser degree Internet piracy. Moreover, our results show that movies that have BitTorrent trackers available on the day of broadcast experience a lower gain in sales than movies that do not have BitTorrent trackers.

However, we also note that our gains in piracy are based almost exclusively on existing trackers. We find very little evidence that movie broadcasts are used as the source material for Internet piracy. We discuss the implications of this finding in more detail below.

\section{Discussion}

Movie studios have argued that the development of unencrypted over-the-air DTV, combined with the integration of the computer and television and the prevalence of piracy on the Internet, places their content at risk. Their concern is that when a movie is shown in an over-the-air broadcast it will lead to increased piracy of that movie and reduced downstream sales. Indeed several studios have argued that the loss in sales from this piracy will be so great that it will be more profitable for them to show their movies on cable and satellite systems (which have copy protections in place) than it will be to show them in over-the-air broadcasts.

The FCC seemed to rely heavily on these concerns in mandating that all DTV demodulators respect "broadcast flag" copy protection in DTV broadcasts. Their concern may have been driven by the possibility that if studios were to withhold movies and other "high value" content from over-the-air broadcasts it would slow the penetration of DTV, thereby delaying or increasing the cost of the United State's transition from analog to digital TV broadcasts.

However, what is striking in this debate is that neither side has presented any empirical evidence of the size of the piracy problem faced by the studios or the impact of over-the-air broadcasts on DVD sales (either in absolute terms or relative to cable channels). In this paper we have gathered a new data set that allows us to analyze these two questions.

We find that after a movie is shown on broadcast TV there is a strong and immediate increase in sales of the corresponding DVD through Amazon.com, and that the sales increase for movies 
shown on broadcast channels is nearly four times larger than the average sales gain for cable movies.

However, at the same time, we also find that broadcast movies are associated with a statistically significant in piracy for corresponding movie files on public BitTorrent trackers, while cable movies show no statistically significant increase in piracy. We also find that DVDs experience a lower sales gain after broadcast when there are BitTorrent trackers available than when no BitTorrent trackers are available.

For broadcasters, our findings suggest that, even in the absence of copy protection, movie broadcasts act as a strong complement to downstream content sales. These gains come on top of the \$3-15 million in revenue studios receive when they license a movie to be broadcast on TV. This result should be encouraging for broadcasters who have long feared that the dominant impact of consumer analog and digital recording devices would be reduced demand for subsequent media purchases. Since the introduction of the VCR, movie studios have argued that if a consumer can record and retain a perfect copy of a movie, TV broadcasts of movies will serve as a substitute for subsequent purchases of the movie content. However, in a digital world this argument may ignore the increased opportunities for studios to differentiate their digital media from the content shown over TV. For example, the increased capacity and random-access capabilities of the DVD format allow studios to include extra content such as commentary tracks, deleted scenes, "behind-the-scenes" documentaries, and music videos. It is also possible that the "hassle" consumers face in copying and storing the broadcast content is sufficiently large to make the commercial purchase an attractive option.

The fact that TV broadcasts serve primarily as complements to subsequent media purchases should also be encouraging for studios increasingly looking to monetize their content through digital download services such as the iTunes video store and other similar services. Indeed the immediate spike in media purchases after a movie is shown on DTV suggest there might be an opportunity for in-program promotion of broadcast content.

However, we also find that movie broadcast tend to stimulate piracy and we find that this increased piracy is correlated with lower DVD sales. At the same time, we also find no evidence that TV broadcasts are used as the source material for Internet piracy, rather the vast majority of 
pirated movies available on the Internet originated from "ripped” DVDs and were available long before the movie broadcast.

This is not surprising for standard NTSC movies since the broadcast quality of the movie will generally be lower than DVD quality, and DVD movies are typically available long before the television broadcast. However, this is somewhat surprising for high definition movies as the high definition television broadcast has a much higher resolution than the DVD version. It is possible that the sheer size of HDTV broadcasts (8.7 Gigabytes/hour when broadcast in 1080i) is prohibitive for most Internet users. It is also possible that Internet “pirates” don't value the additional resolution of HD broadcasts versus DVD resolution to invest the additional time in downloading HD trackers.

However, these factors could change in the future as Internet download speeds increase and as HD displays gain popularity. However, for movie broadcasts to serve as the source material for piracy — the core argument for the broadcast flag — it would have to be the case that equal or superior quality versions were not readily available through pirate sites at the time of the broadcast. This would be dependent on the ability of the movie industry to minimize leaks of High Definition material prior to TV broadcast, which in turn would involve shutting down studio leaks, leaks through the next generation high definition DVD standard, and leaks through "protected” pay cable channels. The extant literature suggests that the industry will face severe challenges in closing leaks in these channels (see Byers et al. (2003) for a discussion of studio leaks, and Perry (2005) for a discussion of digital rights management in next generation High Definition DVD standards).

For policymakers, our results show that, in spite of piracy, over-the-air movie broadcasts result in substantially higher increases in DVD sales than cable broadcasts do. This suggests that movie studios will not find it profitable to remove their "high value" content from (unprotected) overthe-air channels in favor of (protected) cable channels, an action that could have slowed the nation's migration from analog to digital TV. Further, as noted above, consumer groups have identified several reasons to believe that implementing the broadcast flag may retard DTV penetration. Thus, policymakers may wish to consider the possibility that implementing the broadcast flag carries a greater risk of delayed DTV adoption than not implementing the flag will. 
Finally, we note that there are several limitations of our study. First, this study should not be seen as a policy impact statement. We do not observe the counter-factual situation of what would happen to DVD sales in the presence of the broadcast flag regime. Second, our findings may change in the future if the environment surrounding piracy changes. It is possible that an increase in penetration of computer-based HDTV cards, PVRs, or high bandwidth Internet connections will change our results. It is also possible that the movie industry will be able to effectively stop HD piracy from other sources such as industry leaks (Byers et al. 2003), Blu Ray and HD-DVD content, and cable and satellite systems. If this were to occur, unprotected HDTV content could, in the future, become a more significant source of piracy. This would make an interesting area for future research and analysis.

\section{Reference}

ALA. 2004. Opening Brief of Petitioners, American Library Association et al. vs. Federal Communications Commission et al. United States Court of Appeals for the District of Columbia Circuit. Case 04-1037. October 4.

Bhattacharjee, S., R. Gopal, J. Marsden, R. Telang. 2005. The Effect of Digital Sharing Technologies on Music Markets: A Survival Analysis of Albums on Ranking Charts. INFORMS Conference on Information Systems and Technology, November 2005.

Biddle, P., P. England, M. Peinado, B. Willman. 2002. The Darknet and the Future of Content Distribution. 2002 ACM Workshop on Digital Rights Management, November 18. Available from http://crypto.stanford.edu/DRM2002/darknet5.doc. Last accessed January 5, 2006.

Blackburn, D. 2004. On-line Piracy and Recorded Music Sales. Working Paper, Harvard University, Cambridge, MA.

Brynjolfsson, E., Y. Hu, M. Smith. 2003. Consumer Surplus in the Digital Economy: Estimating the Value of Increased Product Variety. Management Science 49(11) 1580-1596.

Burger, J. 2005. Why the broadcast flag won't work. CNET News.com. May 26. Available from http://news.com.com/2102-1071_3-5720006.html. Last accessed January 5, 2006.

Byers, S., L. Cranor, D. Korman, P. McDaniel, E. Cronin. 2003. Analysis of Security Vulnerabilities in the Movie Production and Distribution Process. Proceedings of the $3^{\text {rd }}$ ACM Workshop on Digital Rights Management, Washington DC, pp. 1-12.

Center for Democracy and Technology. 2003. Implications of the Broadcast Flag: A Public Interest Primer (version 2.0). A Report of the Center for Democracy and Technology, December. 
Available from http://www.cdt.org/copyright/031216broadcastflag.pdf. Last accessed January 5, 2006.

Chelappa, R.K., S. Shivendu. 2005. Managing Piracy: Pricing and Sampling Strategies for Digital Experience Goods in Vertically Segmented Markets. Information Systems Research 16(4) 400-417.

Chevalier, J., A. Goolsbee. 2003. Measuring Prices and Price Competition Online: Amazon and Barnes and Noble. Quantitative Marketing and Economics 1(2) 203-222.

Chevalier, J., D. Mayzlin. 2004. The Effect of Word of Mouth on Sales: Online Book Reviews. Working paper, Yale School of Management, New Haven, CT.

Elberse, A., J. Eliashberg. 2003. Demand and Supply Dynamics for Sequentially Released Products in International Markets: The Case of Motion Pictures. Marketing Science 22(3) 329-354.

Epstein, E.J. 2005. The Big Picture: The New Logic of Money and Power in Hollywood. Random House, New York, NY.

FCC. 2003. Report and Order and Further Notice of Proposed Rulemaking, MB Docket 02-230. November 3.

Fox, S. 2002. Comments of the Walt Disney Company and the ABC Television Network, Before the Federal Communications Commission, In the Matter of Digital Broadcast Copy Protection. MB Docket No. 02-230. December 6.

Ghose, A., M.D. Smith, R. Telang. 2006. Internet Exchanges for Used Books: An Empirical Analysis of Product Cannibalization and Welfare Impact. Information Systems Research, 17(1) 3-19.

Ghose, A., A. Sundararajan. 2005. Software Versioning and Quality Degradation? An Exploratory Study of the Evidence. Working Paper. New York University, New York.

Gil, P. 2006. What are the Good BitTorrent Search Engines. February 12. Available from http://netforbeginners.about.com/od/peersharing/f/torrentsearch.htm. Last accessed, February 19, 2006.

Glickman, D. 2005. Testimony of Dan Glickman, Chairman and CEO, Motion Picture Association of America. Before the Subcommittee on Courts, the Internet and Intellectual Property, House Judiciary Committee. U.S. House of Representatives. Oversight Hearing on "Content Protection in the Digital Age: the Broadcast Flag, High-Definition Radio, and the Analog Hole. November 3. Available from http://judiciary.house.gov/OversightTestimony.aspx?ID=505. Last accessed January 5, 2006.

Godwin, M., Sohn, G.B., Murray, C. 2003. Reply Comments of Public Knowledge and Conusmers Union. Before the Federal Communications Commission, In the Matter of Digital Broadcast Copy Protection. MB Docket No. 02-230. February 19. 
Gopal, R., and Sanders, L., 1998. International Software Piracy: Analysis of Key Issues and Impacts. Information Systems Research 9 380-397.

Grover, R. 2005. End of the DVD Party? Business Week Online. July 1. Available from http://www.businessweek.com/bwdaily/dnflash/jul2005/nf2005071_7277_db035.htm. Last accessed January 5, 2006.

Gu, B., V. Mahajan. 2005. "How Much Anti-Piracy Effort is Too Much? - A Study of the Global Software Industry.” Working Paper. McCombs School of Business, University of Texas, Austin, TX. (Available at SSRN: http://ssrn.com/abstract=825165).

Hui, K., I. Png. 2003. Piracy and the Legitimate Demand for Recorded Music. Contributions to Economic Analysis and Policy 2(1).

Kannan, P.K., Sanjay Jain. 2002. Pricing Product Lines of Digital Content: A Model and Application to Online Content Provision. Working Paper, University of Maryland, College Park, MD.

Knox, G., J. Eliashberg. 2005. The Consumer's Rent Versus Buy Decision: The Case of Home Video. Working Paper, The Wharton School, The University of Pennsylvania, Philadelphia, PA.

LeBeau, F.W. 2002. Comments of National Broadcasting Company, Inc. Before the Federal Communications Commission, In the Matter of Digital Broadcast Copy Protection. MB Docket No. 02-230. December 6.

Liebowitz, S.L. 2004. The Elusive Symbiosis: The Impact Of Radio on the Record Industry, $R e$ view of Economic Research on Copyright Issues 1(1) 93-118.

Lucey, A. 2002. Comments of Viacom. Before the Federal Communications Commission, In the Matter of Digital Broadcast Copy Protection. MB Docket No. 02-230. December 6.

Mortimer, J. 2006. Price Discrimination and Technological Innovation: Evidence from the Introduction of DVDs. Working Paper, Harvard University, Cambridge, MA.

Oberholzer F., K. Strumpf. 2004. The Effect of File Sharing on Record Sales: An Empirical Analysis. Working paper, Harvard University, Cambridge, MA.

Pasztor, A. 2006. Report sees sharp growth in digital video recorders. Wall Street Journal, February 20.

PBS. 2005. Now playing...and playing...and playing. PBS Frontline. Available from http://www.pbs.org/wgbh/pages/frontline/shows/hollywood/business/windows.html. Last accessed January 5, 2006.

Peitz, M., P. Waelbroeck. 2003. Piracy of Digital Products: A Critical Review of the Economics Literature. CESifo Working Paper Series No. 1071

Perry, T.S. 2005. DVD Copy Protection: Take 2. IEEE Spectrum, January, pp. 38-39. 
Prasad, A., V. Mahajan. 2003. How Many Pirates should a Software Firm Tolerate? An Analysis of Piracy Protection on the Diffusion of Software. International Journal of Research in Marketing 20 337-353.

Rast, R. 2005. The Dawn of Digital TV. IEEE Spectrum, October pp. 26-31.

Rob, R., J. Waldfogel. 2006. Piracy on the Silver Screen. NBER Working Paper 12010.

Smith, Michael D., Rahul Telang. 2004. Internet Exchanges for Used Goods: A Comparison of Digital and Analog Information Goods. Workshop on Information Systems and Economics (WISE), Washington D.C., December 11-12.

von Lohmann, F., Doctorow, C., Schoen, S.D. 2003. Reply Comments of The Electronic Frontier Foundation. Before the Federal Communications Commission, In the Matter of Digital Broadcast Copy Protection. MB Docket No. 02-230. February 18.

Welborn, A. 2005. Copyright Protection of Digital Television: The 'Broadcast Flag.' Congressional Research Service Report for Congress. Order Code RS22106. May 11. 